\title{
Baş Boyun Kanseri (H\&N) Radyoterapisinde Üç Farklı Hacimsel Ayarlı Ark Terapi (VMAT) Tekniği İle Hedef Hacim ve Kritik Organ Dozlarının Retrospektif İncelenmesi ${ }^{*}$
}

\author{
Ŏguz AYDIN, Candan DEMİR̈Z ABAKAY, Sema GÖZCÜ TUNÇ, \\ Duygu BOLAT, Sibel Kahraman ÇETINTAŞ, Meral KURT
}

Uludağ Üniversitesi Tıp Fakültesi, Radyasyon Onkolojisi Anabilim Dalı, Bursa.

\begin{abstract}
ÖZET
Baş boyun kanseri $(\mathrm{H} \& \mathrm{~N})$ radyoterapisinde hacimsel ayarlı ark terapi (VMAT) tekniği ile hazırlanan üç farklı radyoterapi planında, hedef hacim dozu ve kritik organ dozlarını incelemesi hedeflenmiştir. Çalışmada sekiz baş boyun kanseri (H\&N) tanılı olgu değerlendirildi. Radyoterapi planlarında; çift rotasyon şeklinde 1 ark (sVMAT), çift ark (dVMAT) ve $15^{0}$ kolimatör açılı olacak şekilde (cVMAT) planları hazırlandı. Üç yöntemde hedef hacme reçete edilen doz istenilen şekilde verilebilmiştir. Sağ ve sol parotis $\mathrm{D}_{\text {mean }}$ değerlerinde anlamlı fark gözlenmemiş ancak sağ parotis için sVMAT tekniği daha düşük doz aldığı görülmüştür. Üç farklı planda tümör dozu istenilen şekilde sağlanmıştır ve organ dozlarımız istenilen sınırlar içerisinde tutulabilmiş̦tir. Ancak parotis bezi ve beyin sapında elde edilen düşük doz değeri sVMAT tekniğini diğer tekniklere göre üstün kılmıştır.
\end{abstract}

Anahtar Kelimeler: Baş Boyun Kanseri. Kolimatör açısı. Monaco. VMAT.

Retrospevtive Study of Target Volume and Critical Organ Doses Using Three Volumetric Arc Therapy (VMAT) Techniques in Head and Neck Cancer (H\&N) Radiotherapy

\begin{abstract}
The aim of this study to examine, the target volume dose and critical organ doses in three different radiotherapy plans prepared with the volumetric arc therapy (VMAT) techniques in head and neck cancer (H\&N) radiotherapy. Eight head and neck cancer (H \& N) cases were evaluated in the study. In radiotherapy plans; in the form of double rotation of $1 \operatorname{arc}(\mathrm{sVMAT})$, double arc (dVMAT) and with $15^{\circ}$ colimator angles of two arc (cVMAT) were prepared. In the three methods, the prescribed dose of the target volume could be given in preferenced. No significant difference was showed in the values of the left and right parotid $\mathrm{D}_{\text {mean, }}$, however, the sVMAT technique for the right parotid was found lower dose value. In the three different plans, tumor doses and critical organs doses had been provided within the required limits. However, sVMAT was found superior than other techniques for the parotid gland and brain stem doses.
\end{abstract}

Key Words: Colimator Angle. Head and Neck Cancer (H\&N). Monaco. VMAT.

Baş-boyun bölgesi yerleșimli tümörler tüm kanserlerin \%10'unu, kanserden ölümlerin \%4'ünü oluşturur ${ }^{1}$. Baş boyun bölgesinde çok zengin lenfatik ağı olması sebebiyle geniş tedavi alanlarının tedavi edilmesi zorunludur. Baş boyun RT uygulamalarının da önemli zorluklarından biri tümörün yerleşim yerinden dolayı yakın komşuluğunda çok fazla kritik organ olmasıdır.

* TESNAT 2018 Kongresi'nde (Alanya) sözlü bildiri olarak sunulmuştur.

Geliş Tarihi: 4 Mayıs 2018

Kabul Tarihi: 08 Haziran 2018

Yüksek Lisans Öğrencisi Oğuz AYDIN

Uludağ Üniversitesi Tıp Fakültesi

Radyasyon Onkolojisi Anabilim Dalı

Tel.: 05442020389

E-posta: aoguz246@gmail.com
Bir diğer zorluğumuz bu bölgenin zengin lenfatik ağ1 olmasıyla geniş tedavi alanının ışınlanmasıdır. Kompleks yapısından, kritik organların yaygınlığından ve geniş tedavi alanlarından dolayı bu hasta grubunda yan etki olasılığı artmaktadır². Hastalarda oluşan biyolojik yan etkilerin dışında baş boyun bölgesi yerleşim yeri ile vücudumuzda ilk bakışta görünen bölgemiz olması nedeniyle bu bölgede oluşan hastalığın ve tedavinin yol açtığ fiziksel, kozmetik sorunlar hastalarda duygusal yıkıma sebep olabilmektedir ${ }^{3}$.

Teknolojik gelişmeler sayesinde özellikle kompleks tümörlerde yeni gelişen radyoterapi yöntemleri sayesinde riskli organlar korunurken hedef hacimde yüksek dozlara çıkılabilmektedir. Baş boyun kanseri radyoterapisinde VMAT yöntemi ile YART (Yoğunluk Ayarlı Radyoterapi) ve 3B-KRT (Üç Boyutlu Konformal Radyoterapi) yöntemleri karşılaştırıldığında; VMAT ve YART yöntemlerinde 3B-KRT yöntemine 
göre riskli organlarda daha düşük doz değeri sağlanabilmektedir ${ }^{4}$. Ancak YART tekniğindeki yüksek MU (Monitor Unit) değeri ve tedavi süresinin uzunluğu bu tekniğin dezavantajıdır ${ }^{5,6}$.

VMAT tekniğinde dinamik çok yapraklı kolimatörler (ÇYK) kullanılır ve hasta ışınlanırken gantri hastanın etrafında döner. Gantri dönerken ÇYK sürekli hareket eder ve doz oranındaki varyasyonlarla konformal dağılımlar oluşturarak 1şınlanacak bölgenin tam ve doğru bir şekilde ışınlanmasına, aynı zamanda sağlam dokuların korunmasına olanak sağlar ${ }^{7}$. Bu sebeple tedavi süresi diğer yöntemlere göre oldukça kısalmaktadır. Ancak gantri rotasyonu sırasında düşük doz değerlerinde saçılma fazla olmaktadır ${ }^{8}$.

VMAT tekniğinde kullanılan arklar sayesinde gantri dönerken 1şınlama devam eder ve tedavi süresinde olumlu oranda düşüş sağlanır. Guckenberger $M$. ve arkadaşları yaptıkları çalışmada; çift ark kullanımının daha iyi hedef hacim dozu, CI, HI ve daha az sicak doz bölgesi sağladığını görmekle birlikte 1 ark ile kıyaslandığında daha yüksek MU değeri ve düşük dozun daha fazla saçıldığını gözlemlemişlerdir ${ }^{4,9,10}$.

Kalet A. ve arkadaşları yaptıkları çalışmada Monaco Tedavi Planlama Sisteminin özelliği olan 1 ark çift rotasyon ve iki ark ile hazırladıkları tedavi planları arasında, tedavi süresi açısından \%33 azalma görülmüştür. Bu iki tedavi tekniğinde; kritik organ ve PTV dozu açısından anlamlı fark gözlememişlerdir ${ }^{8}$.

VMAT planları hazırlanırken kullanılabilen bir diğer önemli etki kolimatör açısıdır. Kolimatör açısı, heterojen tümörlerde arzu edilen doz dağılımını daha iyi şekillendirmek ve sağlıklı organ korunmasını sağlayabilmek için uygulanabilir bir parametredir ${ }^{11,12}$.

Bu çalışmada 8 baş boyun kanseri tanılı hastanın üç farklı hacimsel ayarlı ark tedavi planı oluşturulmuş ve sonuçlar dozimetrik olarak karşılaştırılmıştır.

\section{Gereç ve Yöntem}

\section{Hasta Seçimi}

Bu çalışmada Uludağ Üniversitesi Tıp Fakültesi Hastanesi Radyasyon Onkolojisi Anabilim Dalı'nda 15.06.2016- 31.10.2017 tarihleri arasında tedavi görmüş 8 baş boyun kanseri tanılı olgu rastgele seçildi. Hazırlanacak olan sanal tedavi planları için Uludağ Üniversitesi 11 Ocak 2018 tarihli 2018-1/29 nolu etik kurul kararı alınmıştır. Olgulara ait karakteristik özellikler tablo I'de gösterildiği gibidir.
Tablo I. Hastaların karakteristik özellikleri, evrelemesi ve tümör yerleşim yerler

\begin{tabular}{|c|c|c|c|c|c|c|c|}
\hline $\begin{array}{c}\text { Hasta } \\
\text { No }\end{array}$ & Yaş & Cinsiyet & $\begin{array}{c}\text { Tedavi } \\
\text { Yaklaşımı }\end{array}$ & Evre & Yerleşim & $\begin{array}{c}\text { RT Dozu } \\
\text { Gy }\end{array}$ & fx \\
\hline 1 & 61 & Erkek & Küratif & $\begin{array}{c}\text { T3N2C } \\
(\text { Evre 4a) }\end{array}$ & Hipofarinks & $66-60-54$ & 30 \\
\hline 2 & 66 & Erkek & Küratif & $\begin{array}{c}\text { T3N0 } \\
(\text { Evre 3) }\end{array}$ & Larinks & $70-60-56$ & 33 \\
\hline 3 & 58 & Erkek & Post-Operatif & $\begin{array}{c}\text { T4N0 } \\
(\text { Evre 4) }\end{array}$ & Larinks & $60-54-50,4$ & 30 \\
\hline 4 & 62 & Erkek & Küratif & $\begin{array}{c}\text { T1N0 } \\
(\text { Evre 1) }\end{array}$ & Oral Kavite & $60-54$ & 30 \\
\hline 6 & 65 & Erkek & Post-Operatif & $\begin{array}{c}\text { T4N0 } \\
\text { (Evre 4) }\end{array}$ & Larinks & $60-54-50,4$ & 30 \\
\hline 7 & 79 & Erkek & Post-Operatif & $\begin{array}{c}\text { T4N2b } \\
(\text { Evre 4) }\end{array}$ & Larinks & $60-54-50,4$ & 30 \\
\hline 8 & 78 & Erkek & Küratif & $\begin{array}{c}\text { T3N0 } \\
\text { (Evre 3) }\end{array}$ & Larinks & $66-60-54$ & 30 \\
\hline
\end{tabular}

T: Tümör, N: Nodül

\section{Kritik Organ Doz Sınırlamaları}

Hedef hacme istenilen doz verilirken tümörün yakın komşuluğundaki kritik organların korunması önemlidir. Bu sebeple radyoterapi (RT) uygularken tümörün aldığı doz ve kritik organların radyasyona tahammül dozları dikkate alınmalıdır. Biz çalışmamızda kritik organ doz sınırlamalarını tablo II'deki gibi kabul edip planlarımızı bu sınırlamaları dikkate alarak oluşturduk.

Tablo II. Kritik Organ Doz Sinırlamaları

\begin{tabular}{|c|c|c|c|c|c|}
\hline $\begin{array}{c}\text { Beyin } \\
\text { Sapı }\end{array}$ & Parotis & Oral Kavite & Özofagus & $\begin{array}{c}\text { Spinal } \\
\text { Kord }\end{array}$ & Mandibula \\
\hline $\begin{array}{c}\text { Dmax } \leq 54 \\
\text { Gy }\end{array}$ & $\begin{array}{c}\text { Dmean } \leq 26 \\
\text { Gy }\end{array}$ & $\begin{array}{c}\text { Dmean } \leq 40 \\
\text { Gy }\end{array}$ & $\begin{array}{c}\text { Dmean } \leq 34 \\
\text { Gy }\end{array}$ & $\begin{array}{c}\text { Dmax } \leq 40 \\
\text { Gy }\end{array}$ & $\begin{array}{c}\text { Dmax } \leq 60 \\
\text { Gy }\end{array}$ \\
\hline & V30\% $5 \% 50$ & & & & \\
\hline & V20 $\leq 20 c c$ & & & & \\
\hline
\end{tabular}

$\mathrm{D}_{\text {mean }}$ : Mean doz değeri, $\mathrm{D}_{\text {max }}$ : Maksimum doz değeri, $\mathrm{V}_{30 \%}$ : $30 \mathrm{~Gy}$ alan hacim yüzdesi, $\mathrm{V}_{45 \%}$ : $45 \mathrm{~Gy}$ doz alan hacim yüzdesi, $\mathrm{V}_{\text {20cc: }}$ : 20 Gy alan hacim $\mathrm{cm}^{3}$

\section{Tedavi Planlaması}

Hastaların tedavi için kullanılacak olan kesit görüntüleri tedavi planlarının hazırlanacağı Monaco 5.1 Tedavi Planlama Sistemine aktarıldı. Aktarılan kesit görüntüleri üzerinde kritik organ ve hedef hacim konturlamaları Uzman Radyasyon Onkoloğu tarafindan yapıldı. Hastalara üç farklı VMAT yöntemi ile tedavi planları hazırland1. Tedavi planları Monte-Carlo algoritması kullanılarak oluşturulmuştur. Çalışmamızda değişen 1şın kombinasyonları dışında bütün diğer değişkenler sabit tutulmuştur.

\section{sVMAT Planlart}

Çalışmada Monaco 5.1 tedavi sistemine gönderilen kesit görüntüleri kullanıldı. Bu görüntüler ile sVMAT planı oluşturuldu. sVMAT planında saat yönünde $180^{\circ}$ 


\section{H\&N VMAT Planlarının Dozimetrik Olarak İncelenmesi}

den başlayıp $360^{\circ}$ dönen 2 rotasyonlu bir ark kullanıldı. sVMAT planında Grid Size $3 \mathrm{~mm}$ ve minimum segment aralığ $5 \mathrm{~mm}$ olacak şekilde plan oluşturuldu.

\section{dVMAT Planlart}

Çalışmada Monaco 5.1 tedavi sistemine gönderilen kesit görüntüleri kullanıldı. Bu görüntüler ile dVMAT planı oluşturuldu. dVMAT planında saat yönünde $180^{\circ}$ den başlayıp $360^{\circ}$ dönen bir ark ile saat yönünün tersinde $180^{\circ}$ den başlayıp $360^{\circ}$ dönen bir ark toplamda çift ark kullanıldı. dVMAT planında Grid Size 5 mm ve minimum segment aralığı $3 \mathrm{~mm}$ olacak şekilde plan oluşturuldu.

\section{cVMAT Planlart}

cVMAT planında saat yönünde $180^{\circ}$ den başlayıp $360^{\circ}$ dönen $15^{\circ}$ kolimatör açılı bir ark ile saat yönünün tersinde $180^{\circ}$ den başlayıp $360^{\circ}$ dönen $345^{\circ}$ kolimatör açılı bir ark kullanıldı. cVMAT planında Grid Size 3 $\mathrm{mm}$ ve minimum segment aralığ $5 \mathrm{~mm}$ olacak şekilde plan oluşturuldu.

3 farklı VMAT tekniği kullanılarak hazırlanan radyoterapi planlarının izodoz dağılımı Şekil 1'de gösterildiği gibidir.

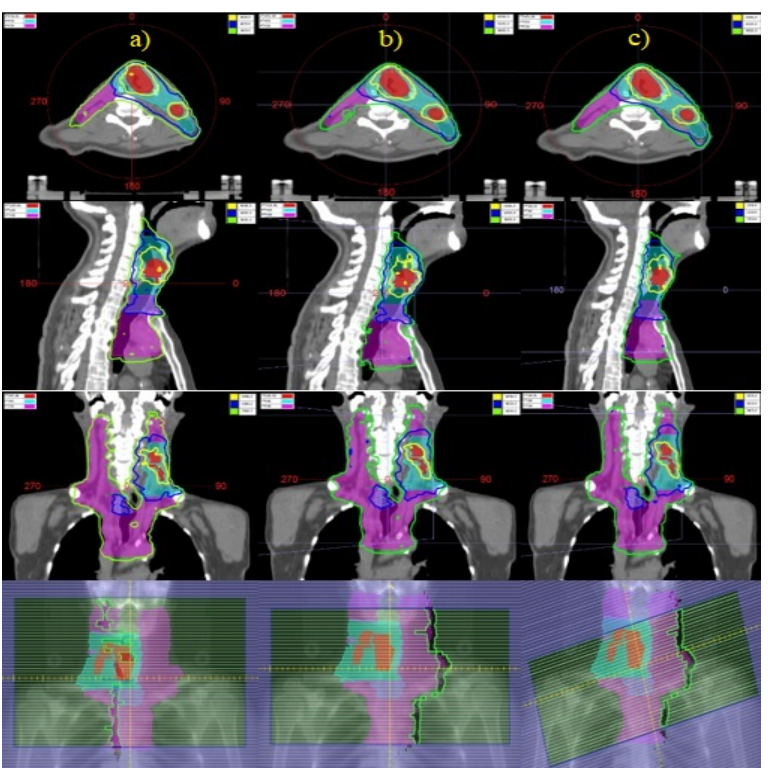

Şekil 1:

a) sVMAT planı izodoz dağılımı, b) dVMAT planı izodoz dağılımı, c) cVMAT planı izodoz dağılımı

\section{Konformite Indeksi (CI)}

CI; hazırladığımız planın tedaviye uygunluğunu ifade eder. Tek başına yeterli bir bilgi vermez fakat planın kalite değerlendirilmesinde kullanılan ölçüm standartlarından biridir. CI 0 ile 1 arasındadır. 1 olması planın ideal olduğunun bir göstergesidir. CI'nin 0'a yaklaşması hedef hacmin istenilen dozu almadığını gösterir ${ }^{13}$.

$$
\mathrm{CI}=\frac{T V_{R I}}{T V} \times \frac{T V_{R I}}{V_{R I}}
$$

$T V_{R I}=$ Referans izodozla sarılı hedef hacim
$T V=$ Hedef hacim

$V_{R I}=$ Referans izodoz hacmi

\section{Homojenite Indeksi (HI)}

HI değeri belirlenen hedef hacim için verilen dozun hacim içerisinde ne kadar homojen, eşit oranlarla dağıldığının göstergesidir. HI değeri 0'a yaklaştıkça planın kalitesi atmaktadır ${ }^{14}$.

$$
\begin{aligned}
& \mathrm{HI}=\frac{D_{362}-D_{9698}}{D_{3650}} \\
& D_{\% 62}=\text { Hedef hacmin \%2'sinin aldığ } 1 \mathrm{doz} \\
& D_{9698}=\text { Hedef hacmin \%98'sinin aldığ } 1 \mathrm{doz} \\
& D_{\% 650}=\text { Hedef hacmin \%50'sinin aldığ } 1 \mathrm{doz}
\end{aligned}
$$

\section{Ístatistiksel Analiz}

Veriler IBM SPSS Statistics20 istatistik programı kullanılarak analiz edilmiştir. sVMAT, dVMAT ve cVMAT planlarında istatistiksel analiz yapılırken, veriler bağımsız değişken olduğu için;

Veriler normal dağılıma uygun, varyanslar homojen ise; One - Way Anova Testi uyguland.

Veriler normal dağllıma uygun, varyanslar homojen değil ise; Kruskal - Wallis Testi uyguland.

Veriler Normal dăğlıma uygun değilse; Kruskal Wallis Testi uygulandi.

Kruskal - Wallis testi sonucunda yöntemler arasında anlamlı fark var ise hangi yöntemler arasında anlamlı fark olduğunu bulmak için Mann - Whitney U Testi uyguland.

Tablolar; veriler normal dağılıma uygun ise Ortalama \pm Standart sapma şeklinde, eğer normal dağılıma uygun değilse ortanca (Minimum- Maksimum) şeklinde oluşturuldu.

\section{Bulgular}

Hedef hacmin aldığı doz değerleri tablo III de gösterilmiştir.

Tablo III. PTV1, PTV2, PTV3, HI, CI ve MU değerleri

\begin{tabular}{|c|c|c|c|c|c|}
\hline \multicolumn{2}{|c|}{$\begin{array}{c}\text { Tümör } \\
\text { Dozları }\end{array}$} & sVMAT & dVMAT & cVMAT & $\begin{array}{c}p \\
\text { Değeri }\end{array}$ \\
\hline \multirow{5}{*}{ PTV1 } & $\mathrm{D}_{2 \%}$ & $62,0(61,3-72,0)$ & $62,2(61,2-72,3)$ & $61,9(61,6-72,1)$ & 0,746 \\
\cline { 2 - 6 } & $\mathrm{D}_{98 \%}$ & $63,4(59,2-72,0)$ & $60,2(59,1-70,5)$ & $60,0(59,9-70,2)$ & 0,878 \\
\cline { 2 - 7 } & $\mathrm{Cl}$ & $1,008 \pm 0,009$ & $1,005 \pm 0,01$ & $1,011 \pm 0,005$ & 0,378 \\
\cline { 2 - 6 } & $\mathrm{HI}$ & $0,062 \pm 0,008$ & $0,063 \pm 0,009$ & $0,059 \pm 0,005$ & 0,647 \\
\cline { 2 - 6 } & $\mathrm{MU}$ & $1381,5 \pm 153,6$ & $1447,1 \pm 131,2$ & $1503,8 \pm 190,0$ & 0,777 \\
\hline \multirow{3}{*}{ PTV2 } & $\mathrm{D}_{98 \%}$ & $54,6(53,8-60,2)$ & $54,4(53,1-60,4)$ & $54,7(54,2-60,8)$ & 0,633 \\
\cline { 2 - 6 } & $\mathrm{Cl}$ & $1,008 \pm 0,006$ & $1,004 \pm 0,01$ & $1,008 \pm 0,009$ & 0,554 \\
\hline \multirow{2}{*}{ PTV3 } & $\mathrm{D}_{98 \%}$ & $52,5 \pm 2,1$ & $52,3 \pm 2,0$ & $52,7 \pm 2,0$ & 0,952 \\
\cline { 2 - 6 } & $\mathrm{Cl}$ & $1,008 \pm 1,01$ & $1,002 \pm 0,015$ & $1,011 \pm 0,012$ & 0,519 \\
\hline
\end{tabular}

$\mathrm{D}_{2 \%}$ : PTV1'nin \%2'lik hacmin aldığ doz değeri, $\mathrm{D}_{98 \%}$ : PTV1, PTV2 ve PTV3' ün \%98'lik hacmin aldığı doz. 
Hazırlanan üç farklı VMAT planında da hedef hacme reçete edilen doz verilebilmiş ama yapılan planın kalitesini belirten faktörlerden biri olan HI değerinde bakıldığında cVMAT planının daha homojen olduğu gözlenmektedir. CI indeks değerlerine bakıldığında ise en konformal doz dağılımı dVMAT tekniğinde sağlanmıştır. Kritik organların aldığı doz değerleri tablo IV'de verildiği gibidir.

Tablo IV: Kritik Organ (OAR) dozları tablosu

\begin{tabular}{|c|c|c|c|c|c|}
\hline \multicolumn{2}{|l|}{ OAR } & $\begin{array}{l}\text { sVMAT } \\
\text { (cGy) }\end{array}$ & $\begin{array}{l}\text { dVMAT } \\
\text { (cGy) }\end{array}$ & $\begin{array}{l}\text { cVMAT } \\
\text { (cGy) }\end{array}$ & $\begin{array}{c}p \\
\text { değeri }\end{array}$ \\
\hline \multirow{2}{*}{$\begin{array}{l}\text { Brain } \\
\text { Stem }\end{array}$} & $D_{\text {mean }}$ & $5,6 \pm 2,6$ & $6,0 \pm 2,9$ & $5,9 \pm 3,0$ & 0,954 \\
\hline & $D_{\max }$ & $\begin{array}{c}33,9(30,7- \\
42,8)\end{array}$ & $\begin{array}{c}37,1(30,7- \\
46,0)\end{array}$ & $\begin{array}{c}38,6(25,8- \\
46,1)\end{array}$ & 0,085 \\
\hline \multirow{3}{*}{$\begin{array}{l}\text { Parotid } \\
\text { Gland R }\end{array}$} & $D_{\text {mean }}$ & $21,5 \pm 3,4$ & $23,7 \pm 3,4$ & $23,1 \pm 3,1$ & 0,412 \\
\hline & $V_{30 \%}$ & $22,63 \pm 6,94$ & $7,74 \pm 8,24$ & $25,63 \pm 7,39$ & 0,412 \\
\hline & $V_{20 c c}$ & $\begin{array}{c}11,383 \pm \\
4,809\end{array}$ & $13,365 \pm 4,031$ & $\begin{array}{c}12,704 \pm \\
4,196\end{array}$ & 0,657 \\
\hline \multirow{3}{*}{$\begin{array}{l}\text { Parotid } \\
\text { Gland L }\end{array}$} & $D_{\text {mean }}$ & $20,5 \pm 2,6$ & & $20,6 \pm 3,1$ & 0,939 \\
\hline & $V_{30 \%}$ & $21,67 \pm 7,76$ & 9,34 & $22,62 \pm 8,24$ & 0,714 \\
\hline & $V_{20 c c}$ & $\begin{array}{c}10,585 \pm \\
3,496\end{array}$ & $11,240 \pm 2,719$ & $\begin{array}{c}10,508 \pm \\
2,865\end{array}$ & 0,87 \\
\hline \multirow{2}{*}{$\begin{array}{c}\text { Esopha- } \\
\text { gus }\end{array}$} & $D_{\text {mean }}$ & $33,0 \pm 10,9$ & 0,5 & $33,4 \pm 10,7$ & 0,997 \\
\hline & $\mathrm{V}_{45 \%}$ & $32,33 \pm 20,00$ & $34,00 \pm 20,04$ & $35,26 \pm 21,06$ & 0,959 \\
\hline $\begin{array}{l}\text { Spinal } \\
\text { Cord }\end{array}$ & $D_{\max }$ & $\begin{array}{c}40,5(32,1- \\
41,7) \\
\end{array}$ & $\begin{array}{c}40,7(32,4- \\
41,3) \\
\end{array}$ & $\begin{array}{c}40,7(32,4- \\
41,2) \\
\end{array}$ & 0,968 \\
\hline $\begin{array}{c}\text { Oral } \\
\text { Cavite }\end{array}$ & Dmean & +16 & $35,4 \pm 2,0$ & $\pm 1,9$ & 0,616 \\
\hline $\begin{array}{l}\text { Subman- } \\
\text { dibular R }\end{array}$ & an & $40,9 \pm 3,6$ & $40,8 \pm 3,6$ & 9 & , 994 \\
\hline $\begin{array}{l}\text { Subman- } \\
\text { dibular L }\end{array}$ & $D_{\text {mean }}$ & $\begin{array}{c}40,8(34,7- \\
46,4)\end{array}$ & $\begin{array}{c}40,9(19,9- \\
45,3)\end{array}$ & $\begin{array}{c}40,8(35,2- \\
45,2) \\
\end{array}$ & 0,983 \\
\hline Mandibula & $D_{\text {max }}$ & $55,1 \pm 10,3$ & $55,7 \pm 9,2$ & $56,6 \pm 9,0$ & 0,957 \\
\hline \multirow{2}{*}{ Lens $\mathrm{R}$} & $D_{\text {mean }}$ & $0,5 \pm 0,2$ & $0,5 \pm 0,1$ & $0,6 \pm 0,2$ & 0,904 \\
\hline & $D_{\max }$ & $0,6 \pm 0,2$ & $0,6 \pm 0,2$ & $0,7 \pm 0,2$ & 0,746 \\
\hline \multirow{2}{*}{ Lens L } & $D_{\text {mean }}$ & $0,5 \pm 0,2$ & $0,5 \pm 0,1$ & $0,5 \pm 0,1$ & 0,791 \\
\hline & $D_{\max }$ & $0,6 \pm 0,3$ & $0,6 \pm 0,2$ & $0,7 \pm 0,2$ & 0,772 \\
\hline \multirow{2}{*}{\begin{tabular}{|c|}
$\begin{array}{c}\text { O. Nerve } \\
\mathrm{R}\end{array}$ \\
\end{tabular}} & $D_{\text {mean }}$ & $0,8 \pm 0,2$ & $0,8 \pm 0,3$ & $0,8 \pm 0,3$ & 0,973 \\
\hline & $D_{\max }$ & $1,0 \pm 0,3$ & $0,9 \pm 0,3$ & $1,0 \pm 0,4$ & 0,905 \\
\hline \multirow[t]{2}{*}{ O. Nerve L } & $D_{\text {mean }}$ & $0,8 \pm 0,2$ & $0,7 \pm 0,2$ & $0,8 \pm 0,2$ & 0,969 \\
\hline & $D_{\max }$ & $1,0 \pm 0,3$ & $0,9 \pm 0,3$ & $0,9 \pm 0,3$ & 0,968 \\
\hline
\end{tabular}

$\mathrm{D}_{\text {mean }}$ : Mean doz değeri, $\mathrm{D}_{\text {max }}$ : Maksimum doz değeri, $\mathrm{V}_{30 \%}: 30 \mathrm{~Gy}$ doz alan hacim yüzdesi, $\mathrm{V}_{45 \%}: 45 \mathrm{~Gy}$ doz alan hacim yüzdesi, $\mathrm{V}_{20 \mathrm{cc}}$ : $20 \mathrm{~Gy}$ alan hacim $\mathrm{cm}^{3}$

Kritik organ doz değerleri incelendiğinde dVMAT ve cVMAT tekniğinin Oral Kavite doz değerini istenilen sınırlar içerinde sağlayamadığı gözlenmektedir.

\section{Tartışma ve Sonuç}

Bu çalışmada; baş boyun kanseri tanılı olgular için hazırlanan üç farklı VMAT tekniğini hedef hacim dozu ve kritik organ dozları açısından karşılaştırmak için Monaco TPS kullandık. Monoco TPS çift ark kullanımı için kullanıcılarına iki yöntem sunmakta; bunlardan birincisi ışın ekleme sekmesinden ikinci bir 1şın eklemektir. Bu yöntemin avantajı kolimatör rotasyonlarına izin vermesidir. İkinci yöntem ise aynı 1şının ikinci kez rotasyonuna izin vermektedir. Bu yöntemle 1şın ikinci kez rotasyon yapmaktadır. İlk yöntem ile ikinci yöntem karşılaştırıldığında ışın sekmesinden yeni ark eklemek yerine 1 arkı çift rotasyon şeklinde döndürmek tedavi süresini olumlu yönde etkilemektedir. 1 ark1 çift rotasyon şeklinde kullanmak segment sayısını arttırmaktadır, MU değeri nispeten aynı kalmaktadır. İki ışın yerine tek ışına iki yay eklendiğinde, Monaco TPS segmentasyon işlemini geliştirir. Esas olarak merkezi, X ekseni boyunca böler. Bir rotasyonda, Monaco TPS tümörün bir yarısını optimize eder. İkinci rotasyon ile, diğer yarısını optimize eder.

Guckenberger M. ve ark. yaptıkları çalışmada; statik YART, 1 ark VMAT (sVMAT), 2 ark VMAT (dVMAT) ve 3 ark VMAT (tVMAT) planlarını dozimetrik olarak karşılaştırmışlardır. Çalışmalarında sonuç olarak; baş boyun bölgesi tanılı olgular için hazırladıkları planlarda sVMAT tekniği ile dVMAT ve tVMAT tekniklerini karşılaştırdıklarında; sVMAT tekniğinde hedef hacme istenilen dozun verilemediğini ve bunun yanında kritik organ dozlarının daha yüksek olduğunu gözlemlemişlerdir ${ }^{4}$.

Dai X. ve ark. 2014 yılında yaptıkları çalışmada; 15 orofarinjiyel kanser tanılı olgunun statik YART ve VMAT yöntemi ile hazırlanmış 1 ark ve 2 ark tedavi planlarını dozimetrik olarak karşılaştırmışlardır. Yaptıkları çalışmada PTV dozu için üç teknik de benzer sonuçlar vermesine rağmen parotis dozunda 2 ark tedavi planlarının, 1 ark planlarına göre daha iyi sonuç verdiğini gözlemlemişlerdir ${ }^{15}$. Bizim çalışmamızda da hazırlanan VMAT planları PTV dozu açısından benzer bulunmuştur.

Benzer bir çalışmada; YART, 1 ark ve 2 ark VMAT planlarını karşılaştırmışlardır. Çalışma sonucunda 1 ark yerine 2 ark kullanımının daha homojen ve konformal doz dağılımı sağladığını ancak özellikle küçük dozdaki saçılmaların daha fazla ve MU değerinin daha yüksek olduğunu gözlemlemişlerdir ${ }^{16}$. Kliniğimizde yapılan çalışma sonuçlarında tedavi planlarının HI ve CI değerleri benzer sonuçlar vermiştir.

YART, VMAT 1 ark ve 2 ark kullanarak hazırlanan başka bir çalışmada tedavi planlarını dozimetrik olarak karşılaştırmışlardır. Çalışmalarının sonucunda YART ve 2 ark VMAT planların, aynı plan kalitesine sahip olduğunu ve iki tekniğin 1 ark tedavi planlarından üstün olduğunu gözlemlemişlerdir. Çalışmalarında baş boyun kanseri tedavisi için, daha kısa tedavi süresi ve daha düşük MU değeri sebebiyle 2 ark tedavi planı YART tekniğinden daha üstün olduğu sonucuna varmışlardır ${ }^{17}$.

Sze H.C.K. ve ark. 2011yılında yaptıkları çalışmada; YART, VMAT 1 ark (SA) ve VMAT 2 ark (DA) radyoterapi yöntemleriyle hazırladıkları planları dozimetrik açıdan karşılaştırmışlardır. Çalışma sonucunda DA yöntemi ile hazırlanan planlarda; SA yöntemi- 


\section{H\&N VMAT Planlarının Dozimetrik Olarak İncelenmesi}

ne göre daha iyi doz sarımı ve daha düşük oranda sıcak nokta oluşumu gözlemlemişlerdir. Bunun yanında DA planlarında daha yüksek MU değeri ve tedavi süresinin \%46 daha uzun olduğu dikkat çekmiştir ${ }^{18}$. Bizim planlarımızda MU değeri anlamlı fark gözlenmese de 1 ark çift rotasyon planlarında daha düşük bulunmuştur.

2009 yılında yapılan benzer bir çalışmada ise 29 baş boyun kanseri (14 orofarinks, 8 hipofarinks ve 7 larinks) tanılı olgu için hazırladıkları YART, 1 ark (RA1) ve 2 ark (RA2) tedavi planlarını dozimetrik olarak karşılaştırmayı amaçlamışlardır. Tedavi planları fraksiyon dozu sirasiyla 2,2 Gy (Gray), 2 Gy ve 1,8 Gy olacak şekilde PTV ${ }_{66}, \mathrm{PTV}_{60}$ ve $\mathrm{PTV}_{54}$ hedef hacimlerine istenilen doz verilirken kritik organların korunması amaçlamışlardır. Çalışma sonuçlarında RA2 tekniğiyle RA1 tekniğine göre daha homojen doz dağılımı elde etmişler ve RA2 tekniğinde kritik organları anlamlı şekilde daha iyi koruyabilmişlerdir. Ancak RA1 tekniğinde daha düşük MU değeri izlemişlerdir ${ }^{19}$. Bizim sonuçlarımızda kritik organlar dozları açısından anlamlı fark gözlenmedi ancak sVMAT planları ile bazı kritik organ dozlarında gözle görülebilir bir düşüş sağlamıştır.

Lee T.F ve arkadaşları; 2011 yılında yaptıkları bir çalışmada, 20 nazofarinjiyel kanser tanılı olgu için hazırladıkları 7 alan YART (7F-IMRT), 18 alan YART (18F-IMRT), $10^{\circ}$ kolimatör açılı 1 ark $\left(\mathrm{SA}_{1}\right)$ ve $10^{0}$ kolimatör açısı içeren 2 ark $\left(\mathrm{SA}_{2}\right)$ radyoterapi planlarını dozimetrik olarak karşılaştırmayı amaçlamışlardır. Çalışmalarında PTV için reçete edilen dozun \%100'ünün hedef hacmin \%95'ini sarması istenmiştir. $\mathrm{SA}_{1}$ tekniği ile hazırlanan planlarda $\mathrm{PTV}_{59,4}$ ve $\mathrm{PTV}_{54}$ istenilen dozu sağlamada yetersiz kalmıştır ve anlamlı şekilde $\mathrm{SA}_{2}$ tekniğinin üstün olduğunu gözlemlemişlerdir. Beyin sap1 $D_{\text {maks }}$, spinal kord $D_{\text {maks, }}$ sağ ve sol parotis $\mathrm{D}_{\text {mean }}$ ve $\mathrm{V}_{30 \%}$ değerlerinde $\mathrm{SA}_{2}$ tekniği anlamlı şekilde üstün bulunmuştur. Bunun yanında $\mathrm{SA}_{2}$ tekniğinde daha az sıcak nokta oluşmuştur. Tedavi planlama süresi, tedavi süresi ve MU değeri $\mathrm{SA}_{2}$ tekniğinin dezavantajı olarak bulunmuştur ${ }^{20}$. Benzer olarak bizim çalışmamızda parotis $D_{\text {mean }}$ ve $\mathrm{V}_{30 \%}$ dozu, beyin sap1 $\mathrm{D}_{\text {mean }}$ ve $\mathrm{D}_{\text {maks }}$ dozunda sVMAT tekniğinin lehine bulunmuştur.

VMAT planlarında uygun kolimatör açısını bulmaya yönelik yapılan bir çalışmada 17 abdominal, baş boyun ve gögüs bölgesi tanılı olguyu değerlendirip; VMAT tekniğinde homojen olmayan tümörler için kullanılabilecek en uygun kolimatör açısını belirlemeyi amaçlamışlardır. Hazırladıkları parçalı ark planları; her ark için en uygun kolimatör açısını hesaplayıp vermişlerdir. Planlarda $40^{\circ}$ rotasyonlu 9 ark [Colli$\left.\operatorname{VMAT}\left(40^{\circ}\right)\right], \quad 60^{\circ}$ rotasyonlu 6 ark [ColliVMAT $\left(60^{\circ}\right)$ ], $90^{\circ}$ rotasyonlu 4 ark [Colli-VMAT $\left(90^{\circ}\right)$ ] ve $120^{\circ}$ rotasyonlu 3 ark [Colli-VMAT $\left(120^{\circ}\right)$ ] şeklinde oluşturulmuş ve bunun dişında $360^{\circ}$ rotasyonlu $0^{0}$ kolimatör açılı Std-VMAT(360 $) 1$ ark kullanarak tedavi planlarını oluşturmuşlardır. 6 baş boyun kanseri tanılı olgu değerlendirildiğinde Colli-VMAT $\left(40^{\circ}\right)$ ve Colli-VMAT $\left(60^{\circ}\right)$ ile hazırlanan planlarda; fazla ark sayısı ile her ark bölgesine denk gelen tümörün, hetorojen şekline uygun kolimatör açısı vermenin hedef hacim doz sarımında ve kritik organların korunmasında avantajları olduğunu gözlenmişlerdir. 17 olgu değerlendirildiğinde parçalı ark ve kolimatör açısı kullanılan planlarda MU değerinin düştüğünü gözlemlemişlerdir. Bu MU azalması Colli-VMAT $\left(40^{\circ}\right)$, Std$\operatorname{VMAT}\left(360^{\circ}\right)$ planları karşılaştırıldığında baş boyun bölgesi, abdominal bölge ve göğüs bölgesi için sirasiyla \%38,1, \%32,5 ve \%31,5 Colli-VMAT $\left(40^{0}\right)$ tedavi planı lehine bulmuşlardır. Tedavi planlarında parçal1 arkların sayısının arttırılması ve her arka uygun kolimatör açısı kullanılması sebebiyle, foton 1şınları tarafından maruz kalınan alanları daha dar gözlemlemişlerdir. Bu etkilere bağlı olarak da hastalarda oluşabilecek ikincil radyasyon riski azaltılabilmiştir. Ahn B.S. ve arkadaşları yaptıkları çalışmada Colli$\operatorname{VMAT}\left(40^{\circ}\right)$ planlarının daha iyi hedef hacim doz sarımı ve kritik organ korumasında daha gelişmiş olduğu sonucuna varmışlardır. Düşük MU değeri sebebiyle Colli-VMAT $\left(40^{\circ}\right)$ planları daha kısa tedavi süresine sahip olduğunu gözlemlemişlerdir ${ }^{21}$.

Bizim çalışmamızın benzeri bir çalışma yapan Kalet A. ve ark. Monaco Tedavi Planlama Sisteminin sunduğu özelliklerden olan 1 ark çift rotasyon özelliği ile hazırladıkları planları, çift ark planları ile karşılaştırmışlardır. Bizde kliniğimizde bu iki tekniğe ek olarak 2 ark ve kolimatör açısı içeren planları karşılaştırdık. Çalışmalarında HI değerleri benzer sonuçlar verirken CI değeri açısından 1 ark çift rotasyon planlarını daha iyi bulmuşlardır. Bizim çalışmamızda HI ve CI değerleri açısından teknikler arasında anlamlı fark gözlenmemiştir. 1 ark çift rotasyon planlarında anlamlı şekilde daha yüksek MU değeri karşılarına çıkmasına rağmen bizim hazırladığımız planlarda anlamlı fark gözlenmemiş ve sVMAT planında daha düşük MU değeri bulunmuştur. Bazı kritik organ dozları açısından 2 ark planlarının 1 ark çift rotasyon planlarına üstün olduğunu sonucuna varmışlardır. Ancak bizim çalışmamızda 1 ark çift rotasyon planları beyin sapı ile parotis doz değerlerinde daha iyi sonuç vermiş ve oral kavite doz değeri sadece 1 ark çift rotasyon planında istenilen sınırlar içerisinde tutulabilmiştir. Yaptıkları çalışmada tedavi süreleri karşılaştırıldığında 2 ark ile hazırlanan planların 1 ark çift rotasyon ile hazırlanan planlara oranla \%33 daha uzun sürdügüüü gözlemlemişlerdir. Bizim çalışmamızda da buna benzer olarak 2 ark planlarının tedavi süresi 1 ark çift rotasyon planlarına göre \%24 daha uzun sürdüğü bulunmuştur ${ }^{8}$.

Özellikle baş boyun gibi kompleks tümörlerde VMAT yöntemi ile hazırlanan 1 ark tedavi planlarında; kritik organları koruyup PTV dozunu sağlayabilmek zor olmakta ve ikinci bir arka ihtiyaç duyulabilmektedir. $\mathrm{Bu}$ sebeple çalışmamızda Monoco TPS'in çift ark 
kullanımı için kullanıcılarına sunduğu iki yöntem incelendi ve buradan hareketle bu etkiyi karşılaştırmak için; 1 ark çift rotasyon, 2 ark ve $15^{\circ}-345^{\circ}$ kolimatör açılı tedavi planları oluşturulup dozimetrik olarak karşılaştırıldı. Hazırladığımız tedavi planları arasında PTV dozları açısından istatistiksel olarak anlamlı fark gözlenmedi. Ancak 1 ark çift rotasyon planlarında bazı kritik organlarda daha iyi dozimetrik sonuçlar elde edilmiştir. Tedavi sürelerini karşılaştırdığımızda; Kalet A. M. ve ark.'nın yaptığı çalışmaya benzer sonuçlara ulaştık. 1 ark çift rotasyon planlarının sırasıyla 2 ark ve kolimatör açılı planlara göre \%23,6 ve \%19,8 kısaldığını gözlemledik.

Sonuç olarak; yaptığımız bu çalışma sonuçlarına göre Monaco TPS'in sunduğu 1 ark çift rotasyon özelliği sayesinde özellikle baş boyun bölgesi gibi kompleks yapıya sahip tümörlerde 1 ark ile yapılan planlardan daha iyi dozimetrik sonuçlar elde etmekteyiz ancak bununla birlikte MU değeri de artış göstermektedir. Monaco TPS'de 2 ark yerine 1 ark çift rotasyon kullandığımız zaman uzun süren tedavi süresini anlamlı şekilde kısaltmaktayız. Biz kliniğimizde yaptığımız bu çalışma sonuçlarına göre tedavi yöntemleri arasında anlamlı fark olmasa da 1 ark çift rotasyon tedavi planlarının daha iyi dozimetrik sonuçlar verdiğini ve bunun yanında tedavi süresinin kısaldığını gözledik. Özellikle tedavi süresinin kısalmasıyla hastaların tedavi süresindeki konforu olumlu yönde etkilenmekte böylece 1şınlama sırasında meydana gelebilecek hasta hareketinden kaynaklı hataların azalabileceğini düşünmekteyiz.

\section{Kaynaklar}

1. Van Luijk P, Pringle S, Deasy J.O., Et Al. Sparing The Region Of The Salivary Gland Containing Stem Cells Preserves Saliva Production After Radiotherapy For Head And Neck Cancer. Science Translational Medicine, 2015, 7.305: 305ra147305 ra147.

2. Kım R, Ock C.-Y., Keam B, Et Al. Predictive And Prognostic Value Of Pet/Ct Imaging And Clinical Decision-Making Consequences In Locally Advanced Head \& Neck Squamous Cell Carcinoma: A Retrospective Study. Bmc Cancer, 2016, 16.1: 116.

3. Pollard A, Burchell J.L., Jastle D, Et Al. Individualised Mindfulness-Based Stress Reduction For Head And Neck Cancer Patients Undergoing Radiotherapy Of Curative Intent: A Descriptive Pilot Study. European Journal Of Cancer Care, 2017, 26.2.

4. Guckenberger M, Richter A, Krieger T, Et Al. Is A Single Arc Sufficient In Volumetric-Modulated Arc Therapy (VMAT) For Complex-Shaped Target Volumes?. Radiotherapy And Oncology, 2009, 93.2: 259-265.

5. Stathakis S, Roland T, Papanikolaou N, Li J, Ma C. Prediction Study On Radiation-Induced Second Malignancies For Imrt Treatment Delivery. Technology In Cancer Research \& Treatment, 2009, 8.2: 141-147.

6. Sivakumar R, Janardhan N, Anuradha C, Et Al. Su-E-T-309: Dosimetric Comparison Of Simultaneous Integrated Boost Treatment Plan Between Intensity Modulated Radiotherapies (Imrts), Dual Arc Volumetric Modulated Arc Therapy (Da-Vmat) And Single Arc Volumetric Modulated Arc Therapy (Sa-Vmat)
For Nasopharyngeal Carcinoma (Npc). Medical Physics, 2015, 42.6part16: 3404-3404.

7. Gomez J, Barrachına M, Sainz I J, Et Al. Potential Advantages Of Volumetric Arc Therapy In Head And Neck Cancer. Head \& Neck, 2015, 37.6: 909-914.

8. Kalet Alan M., Richardson Hannah L., Nikolaisen Darrin A., Et Al. Dosimetric Comparison Of Single-Beam Multi-Arc And 2Beam Multi-Arc VMAT Optimization In The Monaco Treatment Planning System. Medical Dosimetry, 2017, 42.2: 122125.

9. Matuszak M.M., Steers J.M., Long T., Et Al. Fusionarc Optimization: A Hybrid Volumetric Modulated Arc Therapy (Vmat) And Intensity Modulated Radiation Therapy (Imrt) Planning Strategy. Medical Physics, 2013, 40.7.

10. Palma D, Vollans E, James K, Et Al. Volumetric Modulated Arc Therapy For Delivery Of Prostate Radiotherapy: Comparison With Intensity-Modulated Radiotherapy And ThreeDimensional Conformal Radiotherapy. International Journal Of Radiation Oncology• Biology• Physics, 2008, 72.4: 9961001

11. Oddıraju S, Rangaraj D, Papıez L. Su-E-T-384: Combining Multiple Arcs Into A Single Arc For Efficient Delivery. Medical Physics, 2013, 40.6part16: 293-293.

12. Zhang P, Happersett L, Yang Y, Et Al. Optimization Of Collimator Trajectory In Volumetric Modulated Arc Therapy: Development And Evaluation For Paraspinal Sbrt. International Journal Of Radiation Oncology• Biology• Physics, 2010, 77.2: 591-599.

13. Feuvret L, Noël G, Mazeron J-J, Bey P. Conformity index: a review. International Journal of Radiation Oncology• Biology• Physics, 2006, 64.2: 333-342.

14. Cantürk E, Topgul G, Gurler O, Et Al. Endometrium, Serviks Ve Larinks Kanserlerinin Yoğunluk Ayarlı Radyoterapi Tekniğinde Doz Homojenite İndeksinin Kantitatif Olarak Değerlendirilmesi ve Homojenite İndeks Değerlerinin Karşılaştırılmas1. Balıkesir Üniversitesi Fen Bilimleri Enstitüsü Dergisi, 2017, 19.3: $135-140$.

15. Dai X, Zhao Y, Liang Z, Et Al. Volumetric-Modulated Arc Therapy For Oropharyngeal Carcinoma: A Dosimetric And Delivery Efficiency Comparison With Static-Field Imrt. Physica Medica: European Journal Of Medical Physics, 2015, 31.1: 5459 .

16. Zhao, L-R, Zhou Y-B, Sun J-G. Comparison Of Plan Optimization For Single And Dual Volumetric-Modulated Arc Therapy Versus Intensity-Modulated Radiation Therapy During PostMastectomy Regional İrradiation. Oncology Letters, 2016, 11.5: 3389-3394.

17. Alvarez Moret, J, Pohl F, Koelbl O, Dobler B. Evaluation Of Volumetric Modulated Arc Therapy (Vmat) With Oncentra Masterplan ${ }^{\circledR}$ For The Treatment Of Head And Neck Cancer. Radiation Oncology, 2010, 5.1: 110.

18. Sze H.C.K., Lee M.C.H., Hung W.M. Et Al. Rapidarc Radiotherapy Planning For Prostate Cancer: Single-Arc And DoubleArc Techniques Vs. Intensity-Modulated Radiotherapy. Medical Dosimetry, 2012, 37.1: 87-91.

19. Vanetti E, Clivio A, Nicoloni G, Et Al. Volumetric Modulated Arc Radiotherapy For Carcinomas Of The Oro-Pharynx, HypoPharynx And Larynx: A Treatment Planning Comparison With Fixed Field Imrt. Radiotherapy And Oncology, 2009, 92.1: 111117.

20. Lee, T.-F., Ting H.-M., Chao P.-J., Fang F.-M. Dual Arc Volumetric-Modulated Arc Radiotherapy (Vmat) Of Nasopharyngeal Carcinomas: A Simultaneous Integrated Boost Treatment Plan Comparison With Intensity-Modulated Radiotherapies And Single Arc Vmat. Clinical Oncology, 2012, 24.3: 196-207.

21. Ahn B.S., Park S.-Y., Park J.M., Et Al. Dosimetric Effects Of Sectional Adjustments Of Collimator Angles On Volumetric Modulated Arc Therapy For Irregularly-Shaped Targets. Plos One, 2017, 12.4: E0174924. 